\title{
Study of the efficiency of the large-diameter fishing tools with the moving magnetic systems
}

\author{
Taras Romanyshyn, Vasyl Sheketa, Liubomyr Romanyshyn \\ Ivano-Frankivsk National Technical University \\ of Oil and Gas, Ukraine \\ Myroslav Buchynskyi \\ Expertnaftogas LLC, Ukraine
}

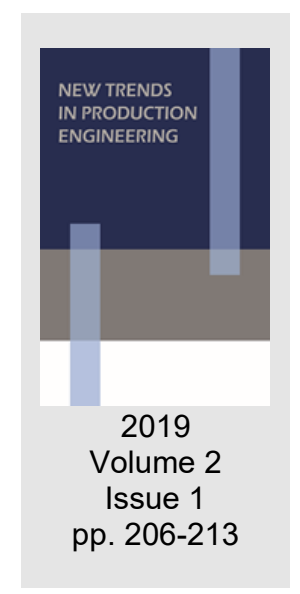

Date of submission to the Editor: 05/2019

Date of acceptance by the Editor: 07/2019

\section{INTRODUCTION}

In the process of drilling of oil and gas wells there are accidents causing the leaving of metal objects of different shapes and masses on the bottom hole (Coll et al., 2012). The construction of mine shafts is also characterized by complications (Kotwica, 2018), which significantly affect the technical and economic performance of drilling operations.

It is known (Douglas, 1999) that fishing tools based on permanent magnet are the most effective for removing ferromagnetic debris from wells. Magnetic fishing tools are used for the removal of whole drill bits, roller cones, bit legs, rolling elements, cutting elements, including hard-alloy, as well as auxiliary tools and foreign objects. The principle of the operation of magnetic tools is completely different from other fishing tools and is to create a magnetic field that interacts with metal objects. The absence of the need for prior destruction of metal objects by devices of magnetic action greatly reduces the duration of fishing operations. The variety of accidents and, consequently, of emergency metal objects on the well bottoms causes the widespread use of magnetic tools. However, known tools have a number of disadvantages. Thus, the essential disadvantages of tools (Johnson et al., 2012) are the ability to self-demagnetization and significant dispersion of magnetic field, which is the cause of low hoisting capacity. The authors (Ermolaev et al., 2016) developed devices with magnetic systems based on permanent ferrite magnets. The disadvantage of these devices is the low durability of the magnetic system due to the rapid wear of the working surface. Substantial changes in the technology of manufacturing of hard-magnetic materials made it possible to develop permanent magnets from rare-earth materials. The use of such magnets in the systems of fishing tools allowed the creation of new designs with higher power and magnetic characteristics (Kryzhanovsky et al., 2014). However, despite the high values of the hoisting capacity, there is a breakaway of the elongated objects during the tool lift as a result of the impact on the walls of the well. 
Considered magnetic tools contain magnetic systems with flat working surfaces. As a result, the contact area of emergency debris with the poles of the magnetic system is much smaller than the area of the working surface of the magnetic cores. This is especially true for dimensional debris and objects of complex geometric shape. Therefore, in order to increase the hoisting capacity, it is first necessary to increase the contact area of the fished object with the magnetic system. This can be achieved in devices in which the magnetic system has the ability to move axially for direct contact with objects and copying their shape.

The attempt to create such tools is realized in the design (Motruk et al., 1986), in which the magnetic system is composed of permanent magnets in the form of spring-loaded rods. However, the disadvantage of this tool is the low reliability of retention and removal of ferromagnetic objects on the surface due to the unreliable operation of the springs and the contact of a ferromagnetic fluid with a drilling mud. In addition, during the rotation of the tool, the destruction of permanent magnets and shafts fixed to them occurs as a result of direct contact with metal objects left in the well.

The feature of the tool (Mirzoyan and Alizade, 1979) is the use of an elastic band, on which fixed magnets are placed. Due to its flexibility and elasticity, the tape freely covers accidental objects of complex geometric shape, thereby increasing the contact area of magnets with emergency items. The disadvantages of the device are the rapid destruction of the elastic tape and permanent magnets due to direct contact with ferromagnetic objects and drilling mud, the loss of fished objects from the cavity of the device due to strikes and vibrations during the lift to the wellhead.

Consequently, based on the analysis of existing designs of magnetic fishing tools, their drawbacks are established. The presence of a flat working surface of a magnetic system does not allow to achieve a sufficient attraction force with objects of complex geometric shape. Tools with a moving system are known only as inventions and are characterized by low reliability of fishing ferromagnetic fragments. Therefore, considerable scientific and practical interest concerns the development of a fundamentally new design of a fishing device of large diameter with moving magnetic systems capable of copying the shape of the objects being fished.

The purpose of the work is to increase the efficiency of removal from the wells objects of irregular geometry by increasing the area of contact with them. To achieve this goal the following tasks are to be solved:

- to develop the design of a tool with mobile magnetic systems;

- to conduct theoretical studies of the working efficiency of the developed tool during the fishing of objects of different shape and position on the well bottom;

- toinvestigate the influence of the material of the fished object on the power characteristics of magnetic systems. 


\section{THE DEVELOPMENT OF DESIGN OF FISHING TOOL WITH MOBILE MAGNETIC SYSTEMS}

The outer diameter of the tool is based on the typical constructions of oil and gas wells, as well as technical wells while the rotor-turbine drilling method for the extraction of solid minerals. The conventional diameter of the rock-cutting tool used to drill such wells is preferably $295 \mathrm{~mm}$. Accordingly, a new design of a magnetic fishing tool with an outer diameter of $270 \mathrm{~mm}$ has been developed for these operating conditions(Romanyshyn and Romanyshyn, 2018).

The tool (Fig. 1) contains an adapter, housing inside which magnetic systems are located and a crown for destroying the layer of sludge on the bottom of the well. Magnetic systems are composed of central and outer cylindrical magnetic cores of opposite polarity, between which there are segmented radially magnetized permanent magnets. Nowadays, the highest magnetic properties have rare-earth neodymium magnets (Gutfleisch, 2000), so neodymium permanent magnets of the chemical composition of $\mathrm{Nd} 2 \mathrm{Fe} 14 \mathrm{~B}$ are used in magnetic systems. Rational geometric relations of magnetic elements systems with a diameter of $72 \mathrm{~mm}$ are determined by the method (Romanyshyn, Dzhus and Romanyshyn, 2017).

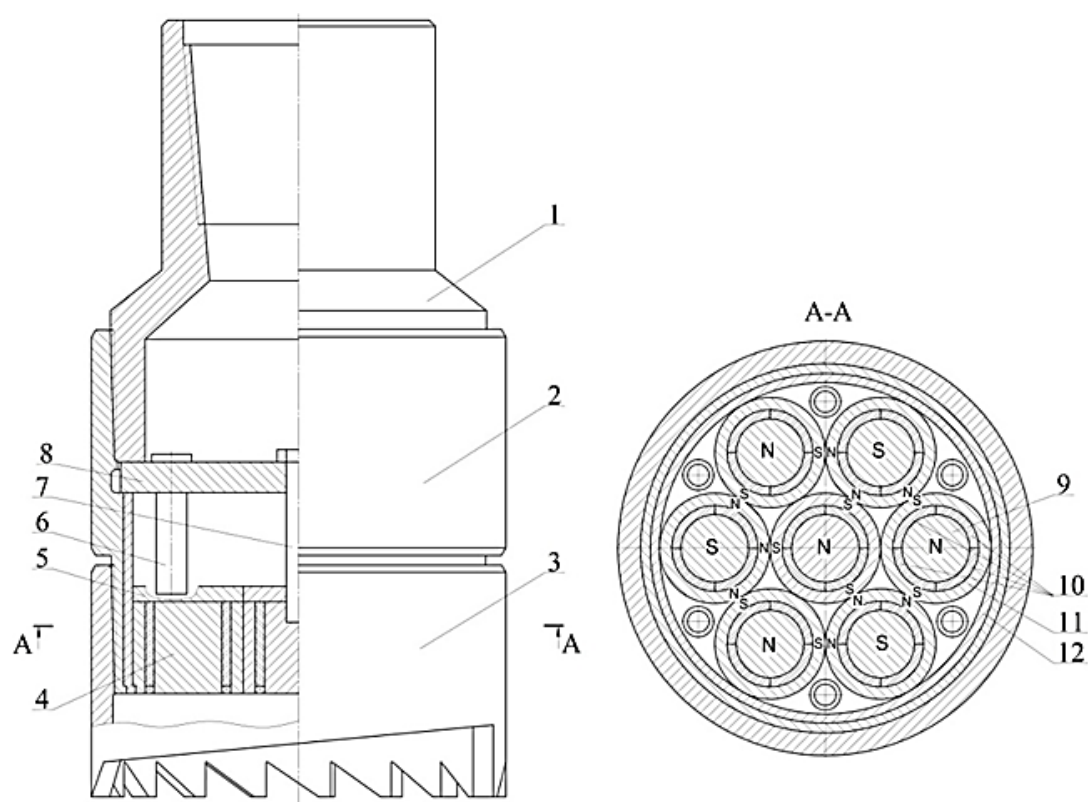

Fig. 1 Magneticfishingtool

1 -adapter; 2 -housing; 3 - millingcrown; 4 - magneticsystem; 5 - diamagneticcover; 6 - washtube; 7 - rod; 8 - disc; 9 - centralmagneticcore; 10 -permanent magnet; 11 - outermagneticcore; 12 - non-magneticliner

Diamagnetic covers are fastened to non-working surfaces of magnetic systems, preventing the scattering of the magnetic flux. Peripheral magnetic systems are installed in a circle in the body and alternately have opposite polarity. Due to the interaction of the magnetic fields of adjacent systems, their mutual fixation and retention in any position occurs. Under the action of the axial force, the magnetic systems move independently from one another and repeat the shape of the 
fished object. In this case, the area of contact with objects of complex geometric shape increases.

The central magnetic system is additionally held in the lower position by a rod and a metal disc. In order to clean the bottom hole and emergency items from the sludge wash tubes are provided. The magnetic systems of the fishing tool are made by demountable, which provides their replacement in case of wear.

\section{METHODOLOGY FOR THEORETICAL RESEARCH}

The main indicator of the purpose of magnetic fishing tool is the hoisting capacity characterizing the magnetic energy in the working gap. To consider the fishing capability of the developed tool, the roller cone of drill bit was selectedas a research object. This object is characterized by a complex geometric shape and often remains on the bottom hole due to jamming of the bearing. It is also possible to leave in a well the whole bit as a result of violation of the rules of fastening or pulling down. Therefore, the interaction of magnetic systems with a three-cone drill bit (IADC Code 415) with adiameter of 115/8" was also investigated.

Three-dimensional models of roller cone, drill bit, as well as magnetic system were created in the SolidWorks program. It was taken into account that on the bottom hole the roller cone can be placed in any position. Therefore, the most probable options of the arrangement of systems in case of fishing the roller cone and drill bit (Fig. 2) are simulated. The calculation of the force of attraction of the objects to a magnetic system was carried out using the finite element method in the ANSYS Maxwell software.

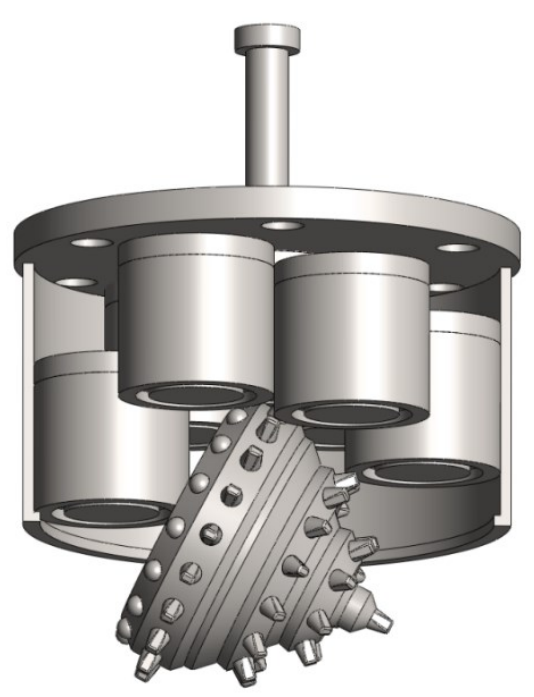

a

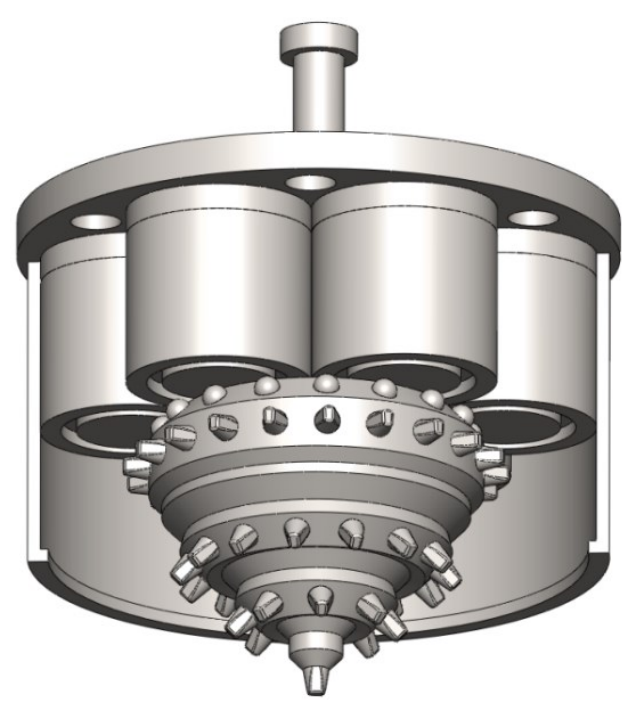

b

Fig. 2 Three-dimensional models of magnetic systems and roller cone of the drill bit with a contact of systems on conical surfaces (a), on end surface (b)

To investigate the impact of the material of an emergency object on the power characteristics of the system in the ANSYS Maxwell program, the force acting on the plate that completely covers the working surface is determined. Steels 1010,3140 and $4813 \mathrm{H}$ (according to ASTM) are used as materials of a plate. 
These materials are used for the manufacture of elements of drill string, rockdestroying and fishing tool. The gap between the working surface of the elementary magnetic system and the plate was set parametrically in the range from $0.01 \mathrm{~mm}$ to $6 \mathrm{~mm}$. This made it possible to establish the dependence of the hoisting capacity on the value of the working gap and to depict traction characteristics.

\section{RESEARCH RESULTS OF EFFICIENCY OF DEVELOPED MAGNETIC FISHING TOOL}

According to the results of theoretical studies, the values of the hoisting capacity were obtained while fishing the roller cone at different positions on the bottom of the well. The Fig. 2a shows the typical position of the roller cone left in the well. One of the magnetic systems is in the extreme lower position, since it does not contact the roller cone. The rest of the systems at the expense of the axial displacement copy the shape of the object being fished. The maximum working stroke of the magnetic system is $58 \mathrm{~mm}$, while the magnetic method of fixing the systems between them is maintained. The hoisting capacity is only $528 \mathrm{~N}$, which is explained by the point contact of the magnetic systems with the surface of the roller cone. In the case of fishing the roller cone on the end surface (Fig. 2b), the hoisting capacity is $2016 \mathrm{~N}$. The increase in the attraction force is due to a significant increase in the contact area of the magnetic cores with the surface of the roller cone.

The hoisting capacity in the case of an attraction of three-cone drill bit is 2759 $\mathrm{N}$. Moreover, the weight of the studied three-cone drill bit is $880 \mathrm{~N}$. In the model under study, the contact is carried out between the working poles of the magnetic systems and the end of the threaded pin connection of the drill bit. In this case, the three-cone drill bit is attracted by four magnetic systems, the three systems are in the extreme lower position and only contact with the fished object with the lateral surfaces. Nevertheless, the mutual fixing of all systems with each other, as well as their retentionin the working position, is maintained.

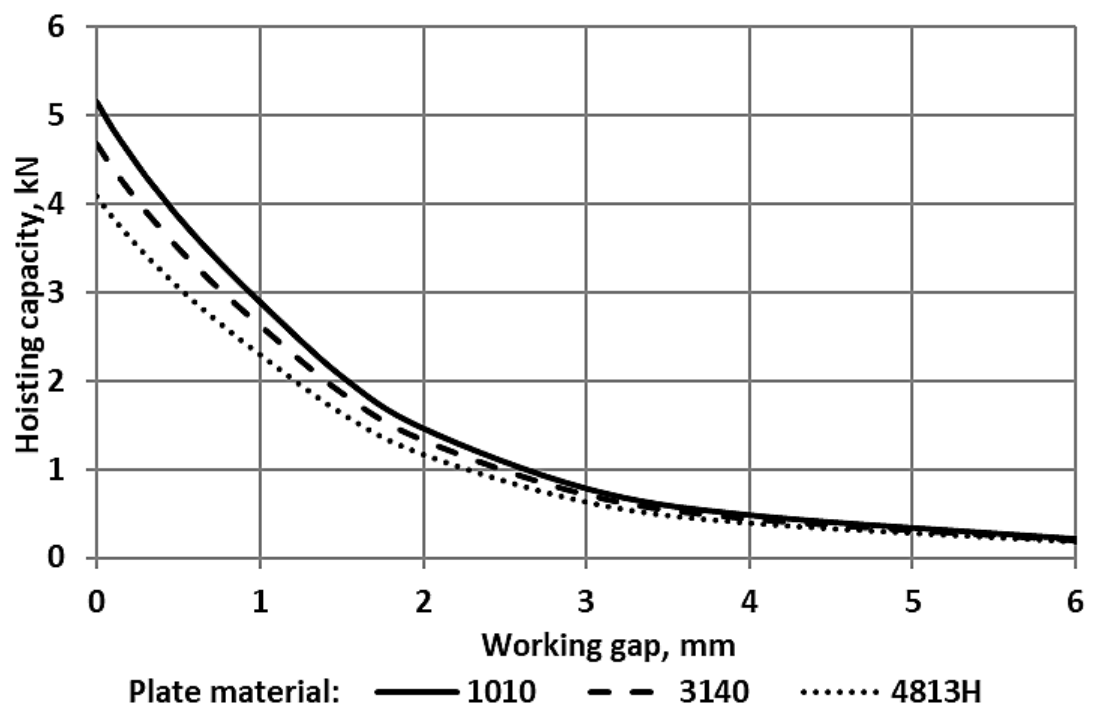

Fig. 3 Traction characteristics of the magnetic system for different materials 
Theoretical studies have established the influence of material of the fishing object on the power characteristics of the magnetic system (Fig. 3). The maximum hoisting capacity of one system is $5.1 \mathrm{kN}$ for plate made from steel 1010. The reduction of hoisting capacity for plates made from steels 3140 and $4813 \mathrm{H}$ is $9-10 \%$ and $20-22 \%$, respectively, compared to plate made from steel1010. The analysis of the obtained traction characteristics gives grounds to assert that all curves have a similar character, namely the reduction of the hoisting capacity with the increase of the working gap. This is due to the fact that the magnetic systems belong to the class of holders.

\section{DISCUSSION OF THE RESULTS OF THE HOISTING CAPACITY STUDY}

Magnetic fishing tool must fish all the ferromagnetic objects located on the bottom of the well. Therefore, their magnetic systems should have the maximum possible hoisting capacity. Many factors influence on the fishing ability of tools. First of all, this is the shape, weight and position of the objects left in the well, as well as the state of the bottom hole. In addition, while raising the fishing toolon the surface, there are vibrations and strokes, which cause the breakaway of elongated fishing objects from the magnetic system. Therefore, for the reliable fishing and removal of emergency metal objects on the surface, the fishing tool must hold objects with a force that is several times greater than its weight.

As the results of theoretical studies show, the developed magnetic tool has quite high power characteristics. Thus, the hoisting capacity during the interaction with the roller cone (Fig. 2a) exceeds its weight by more than 6 times. It is worth noting that such a position on the bottom hole is extremely difficult for fishing. In addition to the irregular geometric shape of the roller cone, there is a hard-alloy cutting elements of considerable height. This leads to point contact with the surfaces of magnetic systems. In the case of the position of the roller cone as shown in Fig. 2b, the hoisting capacity increases by almost 4 times, compared with the previous option. This is due to the fact that the contact occurs along the end surface of the roller cone and the working surfaces of the magnetic systems. Consequently, the results of the calculation confirm the ability of the tool to remove from the wells roller cones at different positions on the bottom hole. Accordingly, it can be argued that other external objects of complex geometric shape can be lifted with a borehole for one lifting operation.

Similar results are obtained when calculating the attraction force to a three-cone drill bit. The hoisting capacity exceeds the bit weight by 3.1 times. Ability to remove drill bits is an important reserve for increasing the efficiency of fishing operations. Since it is known that the removal of entire drill bits from the wells takes much longer than the removal of their elements. It is worth noting that in practice entire rock-destroying tool remains quite rareon the well hole. Significantly more often, there is a jamming of the bearing and the destruction of the roller cones, as a result of which the rolling bearing elements, roller cone or whole sections remain on the bottom of the well.

Another factor influencing the power characteristics of magnetic systems is the material of the objects being fished. The accident analysis shows that on the 
well bottoms most often remain elements of a drill string, rock-destroying and fishing tool. For their manufacture, high-quality structural, alloy and drill bit steels are used. The obtained results (Fig. 3) indicate a slight decrease in the hoisting capacity when interacting with plates made from 3140 and $4813 \mathrm{H}$ steels. This confirms the possibility of fishing emergency items made of alloyed steels. It is worth noting that a tungsten-cobalt hard alloy may also remain on the well bottom, which has weak ferromagnetic properties. Previous studies (Kurnikov et al., 1988) found the possibility of removing hard alloy elements from the well with a force of $15-20 \%$ compared with objects made from steel 1010 .

\section{CONCLUSIONS}

1. The design of a large diameter fishing tool with mobile magnetic systems capable of copying the shape of fished objects has been developed. Due to the increase of the contact area during interaction with emergency objects of complex geometric form, the hoisting capacity significantly increases. Due to the axial displacement of magnetic systems and their mutual retention in the housing with a magnetic field, an increase in the working area and reliableremovalof ferromagnetic debris of different shapes, sizes and masses is provided.

2. According to the results of theoretical studies, the power characteristics of the tool during interaction with objects of irregular geometric shape are determined. It was established that the value of the hoisting capacity exceeds the weight of the roller cone in 6 and 23 times, depending on the position of the object on the well bottom. In the case of interaction with a three-cone drill bit, the attraction force more than 3 times exceeds the bit weight. The obtained results confirm the ability of the developed magnetic tool to remove objects of complex geometric shape, regardless of the position on the bottom of the well.

3. The influence of the material of the fished object on the attraction force to the system is studied and the traction characteristics are depicted. The reduction of the hoisting capacity during the fishing of objects made of alloyed steels is up to $22 \%$. It also confirms the possibility of removing the remaining elements of the drilling and rock-destroying tool.

\section{REFERENCES}

Coll, B., Laws, G., Jenpert, J., Sportelli, M., Svoboda, C. and Trimble, M. (2012).Specialized Tools for Wellbore Debris Recovery.Oilfield Review, [online] Volume 24(4), pp. 4-13. Available at: http://www.slb.com/ /media/Files/resources/oilfield_review/ors12/win12/1_speci alized.pdf. [Accessed 24 Jun. 2019].

Douglas, J. (1999). Fishing techniques for drilling operations. In: Proceedings of AAPG Southwest Section Meeting. [online] Texas, pp. 15-24. Available at: https://oilfieldteam.com/static/uploads/uploaded_files/e0644e69ac296017e1bfbc af294aef92.pdf. [Accessed 24 Jun. 2019].

Ermolaev, A.M., Kobyljanskij, M.T., Bogdanova, T.V. and Kobyljanskij, D.M. (2016).Magnetic catchers as the mean to reduce number of injuries during underground holes drilling.Industrial safety, [online] Volume 1, pp. 89-92. 
Available at: https://cyberleninka.ru/article/v/magnitnye-loviteli-kak-sredstvosnizheniya-travmatizma-pri-burenii-podzemnyh-skvazhin. [Accessed 24 Jun. 2019].

Gutfleisch, O. (2000). Controlling the properties of high energy density permanent magnetic materials by different processing routes.Journal of Physics D: Applied Physics, [online] Volume 33, pp. 157-172. Available at: https://iopscience.iop.org/article/10.1088/0022-3727/33/17/201. [Accessed 24 Jun. 2019].

Johnson, E., Land, J., Lee, M. and Robertson, R. (2012).Landing the big one - the art of fishing.Oilfield Review, [online] Volume 24 (4), pp. 26-35. Available at: http://www.slb.com/ /media/Files/resources/oilfield_review/ors12/win12/3_fish_ art.pdf [Accessed: 24 Jun. 2019].

Kotwica, K. (2018). Atypical and innovative tool, holder and mining head designed for roadheaders used to tunnel and gallery drilling in hard rock. Tunnelling and Underground Space Technology, [online] Volume 82, pp. 493-503. Available at: https://www.sciencedirect.com/science/article/pii/S0886779818303419. [Accessed: 24 Jun. 2019].

Kryzhanovsky, E.I., Raiter, P.N., Romanishin, L.I. and Romanishin, T.L. (2014). Experimental research of characteristics of magnetic systems of the fishing tools. Oil industry, 7, pp. 104-106.

Kurnikov, Y.A., Koncur, I.F., Kobyljanskij, M.T. and Romanyshyn, L.I. (1988).Magnetic fishing tools for well cleaning. L'vov: High school Publishings.

Mirzoyan, Y.G. and Alizade, V.A. (1979).Magnetic mill. 662690.

Motruk, I.Y., Kurnikov, Y.A., Lyah, M.M. and Ischenko, A. M. (1986).Borehole magnetic fishing tool. 1234579.

Romanyshyn, T., Dzhus, A. and Romanyshyn, L. (2017).Design and research of fishing tools with rational parameters of magnetic systems. Eastern-European Journal of Enterprise Technologies, 4 (5), pp. 17-22.

Romanyshyn, T. and Romanyshyn, L. (2018).Magnetic fishing tool. 99790.

\begin{abstract}
.
The variety of accidents which happen during the construction of oil and gas wells causes the expansion in the use of magnetic fishing tools. However, the known tools based on permanent magnets have a significant drawback involving the flat working surface of the magnetic system that does not permit to achieve a considerable attraction force to a fished object of complex geometric shape. Therefore, the aim of the research is to increase the efficiency of removalthe objects of irregular geometric shape from the wells by enlarging the area of contacting them. For that purpose, it has been developed a fundamentally new design of the large-diameter fishing tool with the moving magnetic systems capable of copying the shape of the objects to be fished. Each magnetic system, which is compound of permanent rare-earth neodymium magnets and concentrically placed magnetic cores, shall be held by the magnetic field of adjacent systems with opposite polarity. There were conducted theoretical studies using the finite element method to determine the working capacity of the designed tool. As a result, it has been found the valueof hoisting capacity during the interaction of magnetic systems with the roller cone of the drill bit; this fact confirms the capability of fishing the objects of irregular geometric shape. In addition, it has been explored the influence of the material of the fished object on the power characteristics of magnetic systems. The application of the designed magnetic tool allowsremoving the ferromagnetic objects from the well regardless of their shape, weight and position onthe bottom hole. Apart from that, the given tool may be used in the areas where the technology of work is related to drilling wells.
\end{abstract}

Keywords: fishing tool, magnetic system, permanent magnet, hoisting capacity 